ARTÍCULO ORIGINAL

\title{
Caracterización y comparación de la actividad antibacteriana intrínseca del suero de búfalo y del suero de bovino
}

\author{
Ramírez E, Aguirre S, Patricelli P, Dell’Elce A, Formentini E \\ Laboratorio de Farmacología y Toxicología - Facultad de Ciencias Veterinarias, Universidad Nacional del Litoral \\ * Correspondencia: Enrique Formentini, Facultad de Ciencias Veterinarias, Universidad Nacional del Litoral. R.P. Kreder \\ 2805 (3080) Esperanza, Santa Fe, Argentina. \\ E-mail: eforment@fcv.unl.edu.ar
}

Recibido: 21 Marzo 2017. Aceptado: 4 Julio 2017. Disponible en línea: 10 Julio 2017

Editor: A. Racca

\begin{abstract}
RESUMEN. La actividad antibacteriana de los sueros de bovino y de búfalo fue evaluada in vitro de manera indirecta con dos reacciones de inmunohemólisis: (i) un ensayo de hemólisis-hemoaglutinación sobre eritrocitos no sensibilizados de conejo y (ii) un ensayo de cinética de eritrocitos no sensibilizados de conejo frente a concentraciones crecientes de suero. La actividad bactericida de los sueros fue evaluada in vitro cuantificando la reducción de desarrollo de un inóculo de Escherichia coli en medio de cultivo enriquecido con suero de ambas especies. En el ensayo de hemólisis-hemoaglutinación, la hemólisis máxima se observó hasta la dilución 1:16 del suero de ambas especies. El mayor porcentaje de hemólisis se obtuvo con el suero de búfalo $(84,7 \pm 9,71 \%)$ respecto del suero bovino $(71,0 \pm 5,05 \%)$. Sin embargo no se hallaron diferencias en las diluciones de suero necesarias para obtener el $50 \%$ de la hemólisis total, siendo estas de 10,2 $\pm 2,48$ para el suero de bovinos y de $11,8 \pm 2,18$ para el suero de búfalo. El suero de búfalo redujo el desarrollo bacteriano en un $69,8 \%$ respecto del $47,2 \%$ obtenido por el suero de bovino. No obstante estos resultados, se necesitarán estudios adicionales para corroborar estos hallazgos in vivo.
\end{abstract}

SUMMARY. Characterization and comparison of the antibacterial activity of buffalo and bovine sera. The antibacterial activity of serum of bovine and buffaloes was evaluated in vitro indirectly by two immunohemolysis assays: (i) an unsensitized rabbit blood cells hemolysis-hemagglutination assay and (ii) and a hemolytic-kinetic of unsensitized rabbit blood cells in function of increasing serum concentrations. The serum bactericidal activity was evaluated in vitro by quantifying the reduction of the development of an Escherichia coli inoculum in a culture medium enriched with serum of both species. In the hemolysishemagglutination assay, the máximum haemolysis was observed until a 1:16 serum dilution for both species. The highest percentage of hemolysis was obtained with buffalo serum $(84.7 \pm 9.71 \%)$ with respect to bovine serum $(71.0 \pm 5.05 \%)$. However, no differences were found in the serum dilutions necessary to obtain $50 \%$ of the total hemolysis, being these $10.2 \pm 2.48$ for the serum of cattle and $11.8 \pm 2.18$ for the serum of buffalo. Buffalo serum reduced bacterial growth by $69.8 \%$ compared to $47.2 \%$ obtained by bovine serum. Despite these results, additional studies will be needed to corroborate these findings in vivo.

Palabras clave: Suero de bovino, suero de búfalo, inmunidad innata, inmunohemólisis, actividad bactericida

Key words: bovine serum, buffalo serum, innate immunity, hemolysis, immunohemolysis, antibacterial activity

\section{Introducción}

El búfalo de agua (Bubalus bubalis) ocupa un lugar de importancia en la industria ganadera en muchos países del mundo. En argentina, en los últimos 50 años, se ha comenzado a incorporar esta especie a los sistemas de producción ganadera debido a su fertilidad, longevidad, eficiencia en la conversión alimenticia en la producción de carne, leche y fundamentalmente por su capacidad de adaptación a condiciones ambientales no favorables para las especies de ganado bovino.
En Argentina, hay muchas áreas, donde por condiciones geográficas y ambientales adversas, los sistemas de producción pecuaria basados en especies de ganado bovino no son rentables, y la incorporación del búfalo de agua en estas regiones podría constituir una alternativa para el desarrollo y el mantenimiento de los sistemas de producción pecuaria.

Existe el concepto muy arraigado entre productores pecuarios y Médicos Veterinarios, acerca de que el búbalo de agua presenta una respuesta inmune mucho más robusta y eficaz que la de las razas británicas, índicas o sus cruzas, atribuyendo a esta performance inmunológica, la gran capacidad de adaptación de esta 
especie a condiciones medioambientales hostiles. En ese caso, podría esperarse una mayor eficacia de la respuesta inmune innata o inespecífica en el búfalo de agua que en las razas británicas, índicas o sus cruzas para frenar el avance de infecciones agudas.

Ante el ingreso de patógenos infecciosos a la circulación general tales como virus y bacterias, los anticuerpos naturales (AcN), el complemento (C) y los linfocitos $T$ tempranos independientes o dependientes de los anticuerpos IgM, son cruciales para potenciar la inmunogenicidad y el control eficiente de los patógenos infecciosos y evitar la infección de órganos vitales (Baumgarth et al., 2000).

Los AcN son anticuerpos polirreactivos, producidos sin una estimulación antigénica previa y que están dirigidos hacia antígenos propios y hacia estructuras microbianas comunes como los patrones moleculares asociados a patógenos (PAMP) (Avrameas, 1991).

En los mamíferos, los AcN son IgM (Baumgarth et al., 2005), y son originados por los linfocitos B1 (Baumgarth et al., 2005; Baumgarth, 2013), constituyendo la primera línea de defensa sobre patógenos invasores (Ochsenbein and Zinkernagel, 2000). Los AcN actúan en la etapa de reconocimiento inicial y opsonización de los patógenos que ingresan a la circulación general, contribuyendo a la eliminación de estos por una acción combinada con el $\mathrm{C}$ (dando lugar a la formación del complejo de ataque de membrana), o por fagocitosis (Ehrenstein and Notley, 2010; Hangartner et al., 2006).

La actividad conjunta de los AcN y el C como primera línea de defensa inespecífica ante la invasión de microorganismos a la circulación general, explicarían la actividad bactericida intrínseca del suero. Esta actividad bactericida ha sido observada en el suero de distintas especies animales. Así se observó actividad bactericida de: el suero de bovino (SBo) sobre cepas de Escherichia coli y Staphylococcus aureus (Giacomino et al., 2011), el suero de canino sobre cultivos de Escherichia coli (Giacomino et al., 2012) y el suero de yacaré (caiman latirostris) sobre cultivos de Escherichia coli (Siroski et al., 2015).

Los estudios realizados sobre cinética de inmunohemólisis, muestran que la dilución de suero necesaria para obtener el $50 \%$ de la hemólisis total de una suspensión estandarizada de eritrocitos $\left(\mathrm{CH}_{50}\right)$, es un parámetro útil para establecer diferencias entre sueros respecto de la magnitud de la actividad inmunohemolítica de éstos, ya sea de una misma especie o entre sueros de distintas especies (Oyekan and Barta, 1980; Arya and Goel, 1992; Jaskowski et al., 1999; Costabile, 2010; Moreno-Indias et al., 2012; Grumach et al., 2014).

En vista de lo expuesto, y a los fines de determinar diferencias en la magnitud de la actividad hemolítica del SBo y el suero de búfalos (SBu), por acción de los componentes del sistema inmune innato ( $\mathrm{AcN}$ y $\mathrm{C}$ ) presentes en estos, es que se plantearon dos objetivos:

El primero consistió en evaluar la actividad conjunta de los AcN y el C presentes en el SBo y el SBu mediante reacciones de inmunohemólisis sobre eritrocitos no sensibilizados de conejo (ERC). La utilización de ERC se fundamenta en que si eritrocitos de una especie filogenéticamente distante de los bovinos y búfalos se introdujeran en la circulación general de estos, estas células se comportarán como antígenos, que primero serían opsonizados por los AcN seguidos por la activación de la vía clásica del $\mathrm{C}$, dando como resultado la formación del complejo de ataque de membrana y la posterior lisis de los mismos (Lindoro, 2010).

En pos de este objetivo, se plantearon dos tipos de ensayos: (i) un ensayo de hemólisis-hemoaglutinación $(\mathrm{H}-\mathrm{H})$ para determinar la máxima la dilución de suero de cada especie capaz de producir hemólisis total, y (ii) un ensayo de curva de hemólisis en función de concentraciones crecientes de suero a fin de estimar el valor de $\mathrm{CH}_{50}$ para el suero de cada especie.

El segundo objetivo consistió en evaluar la actividad bactericida intrínseca de los SBo y SBu. Para ello se realizaron curvas de crecimiento bacteriano de Escherichia coli en medio de cultivo estándar y enriquecido con SBo y SBu, evaluando la actividad bactericida intrínseca de los sueros de ambas especies en función de la magnitud de la reducción del desarrollo de la masa bacteriana luego de $24 \mathrm{~h}$ de exposición a estos.

\section{Materiales y Métodos}

\section{Suero de bovino (SBo) y suero de búfalo (SBu)}

El suero se obtuvo a partir de muestras de sangre de cinco vacas Holstein y cinco búfalos de agua. Todos los animales eran machos adultos castrados, clínicamente sanos y que no habían recibido ningún tipo de tratamiento durante los tres meses previos a la toma de las muestras de sangre. La esterilidad de los sueros fue comprobada mediante procedimientos bacteriológicos clásicos (OIE, 2008).

\section{Eritrocitos no sensibilizados de conejo (ERC)}

El día del ensayo, se obtuvo de un conejo (Oryctogalus cuniculus) un volumen de $5 \mathrm{~mL}$ de sangre venosa. La sangre fue trasvasada dentro de un tubo heparinizado y este para su conservación fue refrigerado durante un período no mayor a una hora. Posteriormente, la sangre fue centrifugada a $1500 \mathrm{~g}$ durante $10 \mathrm{~min}$ y posteriormente se registró el volumen total de la muestra y el volumen total del paquete de células sanguíneas. Posteriormente, el plasma fue descartado y el paquete celular fue lavado y suspendido con una 
solución fría de buffer salino monofosfato $0,01 \mathrm{M}$ (PSB) con $\mathrm{pH} 7,4$. Este procedimiento se repitió cuatro veces antes de realizar la centrifugación final. Luego de descartar el sobrenadante, se realizaron diluciones seriadas hasta lograr que la concentración de eritrocitos fuera del $2 \%$ respecto del volumen inicial del paquete celular.

\section{Ensayo de hemólisis-hemoaglutinación (H-H)}

La actividad hemolítica y hemoaglutinante del SBo y del SBu sobre ERC se determinó con el método reportado por Matson et al. (2005). El ensayo se realizó en microplacas de 96 pocillos con fondo redondo en forma de $U$. Con el suero de cada animal (bovino o búfalo) el procedimiento realizado fue el siguiente: en una fila, $25 \mu \mathrm{L}$ de suero fueron depositados en la primera y la segunda celda. Posteriormente $25 \mu \mathrm{L}$ de PBS se depositó en las celdas 2 hasta la 12 inclusive. A partir del contenido de la celda 2 , se tomaron $25 \mathrm{v} \mu \mathrm{L}$ que se depositaron en la celda 3 y se continuó de la misma manera hasta la celda 11 inclusive, descartando los $25 \mu \mathrm{L}$ de esta celda, resultando así una serie de diluciones de suero de 0 a 1:1024. Los $25 \mu \mathrm{L}$ de PBS de la celda 12 se utilizaron como control negativo. Seguidamente $25 \mu \mathrm{L}$ de la suspensión de ERC al $2 \%$ en PBS fueron depositados en todas las celdas (1 a 12), reduciéndose la concentración de SBo y SCo y de ERC en un 50\% y resultando en una concentración de ERC de $1 \%$ e incrementando las diluciones de suero de 1:2 a 1:2048. Luego de finalizado este procedimiento para todas las muestras de SBo $(n=5)$ y SBu $(n=5)$, las microplacas fueron cubiertas con su tapa, y agitadas en forma horizontal con suavidad durante 10 segundos. Posteriormente se incubaron en baño termostatizado a $37^{\circ} \mathrm{C}$ durante 90 min. Luego de finalizada la incubación, cada placa fue inclinada en un ángulo de $45^{\circ}$ durante 20 min para facilitar la visualización de la aglutinación. Luego de mantener cada placa a temperatura ambiente durante $70 \mathrm{~min}$, estas fueron inspeccionadas visualmente para determinar las celdas en donde se produjo la actividad hemolítica. Las celdas (con sus diluciones de suero) que presentaron hemólisis y la aglutinación de ERC fueron identificadas y registradas.

Ensayo de hemólisis de ERC basado en concentraciones crecientes de suero

Para realizar este ensayo se utilizó la técnica reportada por Siroski et al. (2010) modificada. Para el análisis de la actividad hemolítica del suero de cada especie, se utilizaron dos series de 10 tubos de Kant (A y B). La serie A se utilizó para evaluar la actividad hemolítica y la serie $\mathrm{B}$ se reservó como testigo negativo. Para cada serie de tubos, $200 \mu \mathrm{L}$ de SBo o de SBu se colocaron en los tubos $n^{\circ} 1$ y 2 . Seguidamente $200 \mu \mathrm{L}$ de PBS en los tubos $\mathrm{n}^{\circ} 2$ al 9 , y $200 \mu \mathrm{L}$ de agua destilada fueron colocados en el tubo $n^{\circ} 10$. A partir del contenido del tubo $\mathrm{n}^{\circ} 2$, se tomaron $200 \mu \mathrm{L}$ del contenido y se trasvasaron al tubo $n^{\circ} 3$. Este proceso de dilución seriada (1:2) se continuó hasta el tubo 8 inclusive, procediendo a descartar de este $200 \mu \mathrm{L}$ de su volumen final. De esta manera todos los tubos presentaron un volumen final de $200 \mu \mathrm{L}$, y los tubos numerados del 1 al 8 presentaron diluciones de suero de 1:1 a 1:128.

El tubo $n^{\circ} 9$ fue reservado como control negativo (sin hemólisis) y el tubo $n^{\circ} 10$ que contenía solo agua destilada se tomó como control de hemólisis total. Un volumen de $200 \mu \mathrm{L}$ de la suspensión de ERC al $2 \%$ fue colocada en todos los tubos de la serie A y $200 \mu \mathrm{L}$ de agua destilada fueron colocados en todos los tubos de la serie $\mathrm{B}$, produciendo una reducción de la concentración de suero del $50 \%$, resultado en una concentración de ERC al 1\% y diluciones de suero de 1:2 a 1:256.

Una vez finalizado este procedimiento, todos los tubos de las dos series fueron agitados suavemente en vórtex durante 10 segundos e incubados en baño termostatizado a $37^{\circ} \mathrm{C}$ durante $90 \mathrm{~min}$. Posteriormente todos los tubos fueron centrifugados a $1500 \mathrm{~g}$ durante $5 \mathrm{~min}$

Seguidamente, se retiraron $100 \mu \mathrm{L}$ del sobrenadante de cada uno de los tubos de cada serie y fueron colocados en una placa de 96 pocillos ( 8 filas y 20 columnas) con fondo redondeado en forma de $\mathrm{U}$.

La densidad óptica (DO) de las series A y $B$ de todas las muestras de SBo $(n=5)$ y SBu $(n=5)$ fueron leídas en un lector de microplacas (Thermo Labsystems Multiskan RC) a una longitud de onda de $540 \mathrm{~nm}$. Cada una de las muestras de suero de cada especie fue analizada por duplicado y la DO obtenida en cada una de las diluciones fue expresada como promedio.

La actividad hemolítica de cada una de las diluciones de suero fue expresada como porcentaje de la actividad hemolítica máxima observada en el tubo $n^{\circ} 10$, producto de la hemólisis producida tras la exposición de la suspensión de ERC al agua destilada. El porcentaje de hemólisis se calculó a partir de los valores de DO obtenidos en la serie A y B utilizando la siguiente ecuación:

Porcentaje de hemólisis $=\left[\left(\mathrm{DO}_{\mathrm{A}}-\mathrm{DO}_{\mathrm{B}}\right) /\left(\mathrm{DO}_{\mathrm{HM}}\right)\right] \times 100$

Donde $\mathrm{DO}_{\mathrm{A}}$ es la densidad óptica de la dilución de suero de la serie $\mathrm{A}$ y $\mathrm{DO}_{\mathrm{B}}$ es la densidad óptica de la dilución de suero homóloga de la serie $\mathrm{B}$, y $\mathrm{DO}_{\mathrm{HM}}$ ) es la den-sidad óptica correspondiente a la máxima actividad hemolítica observada en el tubo $n^{\circ} 10$.

\section{Análisis de la cinética de hemólisis con el modelo de Hill más respuesta de base}

El modelo sigmoideo de respuesta máxima o de Hill más respuesta de base, es una ecuación con cuatro parámetros utilizada para describir la relación no lineal entre dos variables (Gouthele et al., 2008) y que aquí fue usada para describir la relación entre el porcentaje de hemólisis (variable dependiente) y la dilución de 
suero (variable independiente), la cual a los fines de facilitar el cálculo numérico, se expresó como porcentaje de suero según la siguiente ecuación:

$$
\text { Porcentaje de suero }=(1 / F D) \times 100
$$

donde FD es el factor de dilución que corresponde al segundo término de la notación de la dilución, ej: en una dilución 1:2, el FD corresponde al número 2 .

$$
H=H_{0}+\left(\frac{H_{\max } \cdot x^{n}}{S_{50}^{n}+x^{n}}\right)
$$

Donde $H_{0}$ es el porcentaje de hemólisis basal, $H_{\max }$ es el máximo porcentaje de hemólisis, $S_{50}$ es el porcentaje de suero que produce el $50 \%$ de hemólisis, $x$ es la cantidad de suero expresado en porcentaje y $n$ es el coeficiente de sigmoidicidad. El valor de la dilución de suero que produce el $50 \%$ de la hemólisis $\left(\mathrm{CH}_{50}\right)$ fue estimado como $100 / S_{50}$. Las curvas de hemólisis (porcentaje de hemólisis versus porcentaje de suero) fueron ajustadas con el modelo sigmoideo de respuesta máxima o de Hill más respuesta de base mediante regresión no lineal ponderada de mínimos usando el software ADAPT II (BMSR, University of Southern California, USA). En todos los casos, el ajuste se realizó sobre los datos experimentales sin transformar, utilizando el esquema de ponderación $1 / x^{2}$. El análisis estadístico de los resultados fue realizado con el test estadístico de ANOVA, fijando el límite de significancia al $5 \%(p=0,05)$.

\section{Microorganismo y medios de cultivo}

Se utilizó una cepa autóctona de Escherichia coli (09684), aislada de un ternero con signos de gastroenteritis e identificada por múltiplex PCR para factores de virulencia (Frank et al., 1998). Los medios de cultivo utilizados fueron Caldo Mueller Hinton $(\mathrm{CMH})$ y Agar Mueller Hinton (Britania, Argentina).

\section{Inóculo bacteriano}

El inóculo se preparó a partir de colonias de Escherichia coli (09-684), incubadas sobre placas de agar durante $24 \mathrm{~h}$ a $35 \pm 0,1^{\circ} \mathrm{C}$. Los microorganismos fueron suspendidos en solución isotónica estéril hasta lograr una turbidez equivalente a un valor de 0,5 de la escala de McFarland ( $1 \times 10^{8}$ unidades formadoras de colonia $[\mathrm{ufc}] / \mathrm{mL}$ ). Posteriormente se realizaron diluciones seriadas hasta obtener una concentración bacteriana final aproximada de $0,5 \times 10^{6} \mathrm{ufc} / \mathrm{mL}$.

\section{Construcción de curvas de crecimiento bacteriano}

Los inóculos bacterianos $\left(0,5 \times 10^{6} \mathrm{ufc} / \mathrm{mL}\right)$ en caldo $\mathrm{CMH}, \mathrm{CMH}$ y SBo en proporción 50:50 (CMH-SBo) y $\mathrm{CMH}$ y $\mathrm{SBu}$ en proporción 50:50 (CMH-SBu) fueron incubados a $35 \pm 0,1^{\circ} \mathrm{C}$ durante $24 \mathrm{~h}$. De cada uno de ellos se extrajeron alícuotas de $100 \mu \mathrm{L}$ a los siguientes tiempos: $0,1,2,3,5,5,10$ y 24 h. Cada una de esas alícuotas fue diluida en solución fisiológica estéril y $100 \mu \mathrm{L}$ fueron extendidos sobre la superficie de una placa de agar Mueller Hinton. La dilución proveniente de cada muestra fue sembrada por duplicado y las placas se incubaron en estufa a $35 \pm 0,1^{\circ} \mathrm{C}$ durante 24 $\mathrm{h}$, luego de lo cual se procedió al conteo de ufc/placa. El $n^{\circ}$ de ufc/mL en cada tiempo de muestreo se estimó multiplicando el $n^{\circ}$ de ufc/placa por un factor derivado de las diluciones de cada muestra y se expresó como valor promedio $(n=2)$.

Evaluación del efecto del SBo y del SBu sobre el crecimiento de Escherichia coli (09-684)

La integral de ufc/mL en función del tiempo ( $A B C$ ) se utilizó como parámetro estimador de la masa bacteriana desarrollada en las curvas de crecimiento de Escherichia coli (09-684) en $\mathrm{CMH}, \mathrm{CMH}-\mathrm{SB}$ y $\mathrm{CMH}-$ $\mathrm{SBu}$ (Firsov et al., 1997). Los valores de las integrales en cada medio de cultivo fueron estimadas desde tiempo cero $\left(t_{0}\right)$ hasta las $24 \mathrm{~h}\left(\mathrm{t}_{0}-\mathrm{t}_{24}\right)$ y se calcularon con el método trapezoidal (Baggot, 2001). Para facilitar el cálculo de las integrales, los valores de ufc/mL de cada tiempo de muestreo fueron expresados como porcentaje del número de ufc/mL observadas a $\mathrm{t}_{0}$.

La magnitud de la actividad antibacteriana intrínseca de SBo y SBu se expresó como porcentaje de reducción de la masa bacteriana en presencia de los mismos respecto del valor del $\mathrm{ABC}$ obtenido en $\mathrm{CMH}$.

\section{Resultados}

\section{Ensayo de hemólisis-hemoaglutinación (H-H)}

En el ensayo de $\mathrm{H}-\mathrm{H}$, en todas las muestras de $\mathrm{SBo}(\mathrm{n}=$ 5) y $\operatorname{SBu}(n=5)$ la hemólisis máxima de ERC fue observada hasta la dilución de suero 1:16 inclusive, también se observó una reacción de aglutinación en la dilución de suero 1:32, mientras que en el resto de las diluciones no se observó ningún tipo de reacción (Figura 1).

\section{Cinética de hemólisis analizada con el modelo de Hill} más respuesta de base

Los valores del porcentaje de hemólisis de ERC por concentraciones crecientes de SBo y SBu expresadas como porcentaje, describieron curvas que pudieron ser adecuadamente ajustadas por el modelo sigmoideo de respuesta máxima o de Hill más respuesta de base. Los valores del \% de hemólisis promedio $(n=5)$ para SBo y SBu, su correspondiente desvío estándar y los valores estimados por regresión no lineal ponderada son presentados en la Figura 2. 
$\begin{array}{lllllll}1: 2 & 1: 4 & 1: 8 & 1: 16 & 1: 32 & 1: 64 & 1: 128\end{array}$

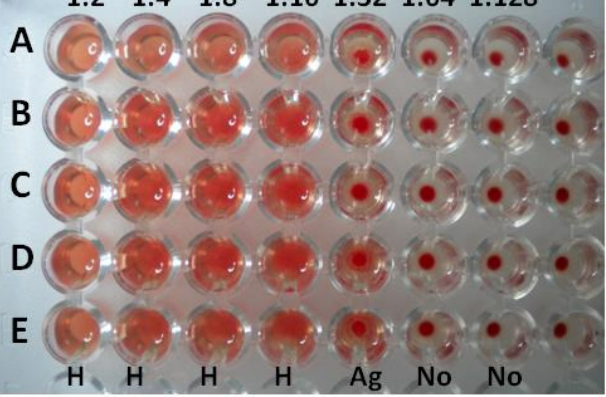

$\begin{array}{lllllll}1: 2 & 1: 4 & 1: 8 & 1: 16 & 1: 32 & 1: 64 & 1: 128\end{array}$

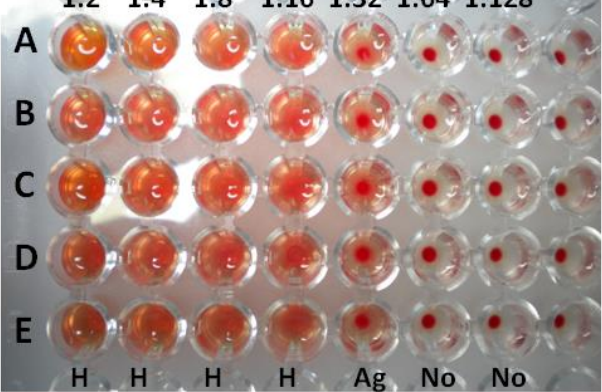

B

Figura 1: Ensayo hemolisis-hemoaglutinación de eritrocitos no sensibilizados de conejo en presencia de diluciones seriadas de suero de (A) cinco bovinos adultos y (B) cinco búfalos adultos (filas A, B, C, D, y E). Las diluciones 1: 2 a 1:16 (columnas 1 a 4) muestran hemólisis (H) y la dilución 1:32 (columna 5) mues-tra hemoaglutinación (Ag). Las diluciones restantes muestran ausencia de hemolisis-hemoaglutinación (No)

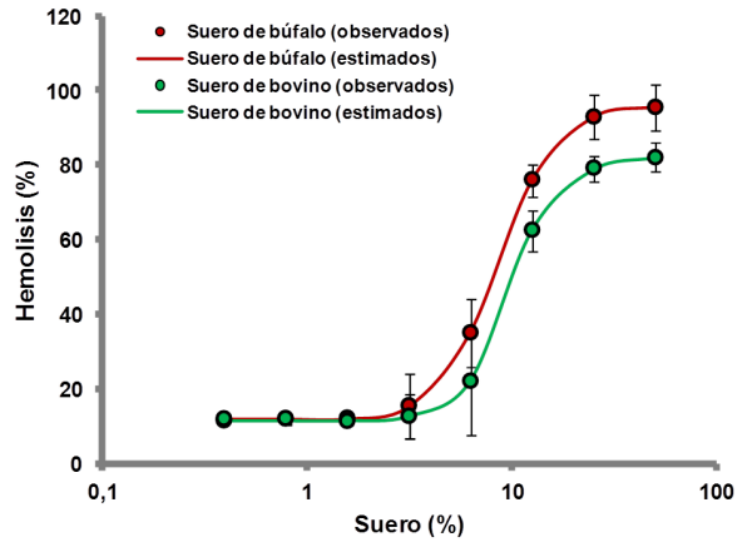

Figura 2: Gráfica semilogarítmica de curvas de hemólisis de eritrocitos no sensibilizados de conejo expuestos a concentraciones crecientes de suero de bovino y suero de búfalo. Los resultados se presentan como porcentaje de hemólisis máxima versus porcentaje de suero. Cada valor observado se expresa como promedio $(n=5)$ y desviación estándar. Las líneas de puntos corresponden a los valores estimados por regresión no lineal ponderada de mínimos cuadrados usando el modelo sigmoideo de respuesta máxima Hill con respuesta de base.

Los valores de los parámetros estimados por el ajuste de los datos experimentales con el modelo de Hill más respuesta de base, se presentan en la Tabla 1.
Tabla 1: Parámetros de la cinética de hemólisis de los eritrocitos no sensibilizados de conejo en función de concentraciones crecientes de suero de bovino y de búfalo, estimados por ajuste de los datos experimentales mediante regresión no lineal ponderada de mínimos cuadrados con el modelo de respuesta máxima o de Hill más respuesta de base. Los datos se expresan como promedio, desvío estándar (DE), coeficiente de variación (CV) y límite inferior (Inf) y superior (Sup) del intervalo de confianza al 95\% (IC95\%). $H_{0}$ es la hemólisis basal expresada como porcentaje, originada por los procedimientos mecánicos del ensayo y que no son atribuibles a la actividad hemolítica de los sueros, $H_{\max }$ es la actividad hemolítica máxima expresada como porcentaje, $S_{50}$ el porcentaje de suero necesario para obtener la mitad de la máxima hemólisis observada, $\mathrm{CH}_{50}$ es la dilución de suero necesaria para obtener la mitad de la hemólisis máxima observada y $n$ es el coeficiente de sigmoidicidad o de Hill que mide la sensibilidad de la respuesta hemolítica de los sueros.

\begin{tabular}{lcccccc}
\hline Parámetros & Especie & $\begin{array}{c}\text { Promedio } \\
(\mathbf{n = 5 )}\end{array}$ & DE & $\begin{array}{c}\mathrm{CV} \\
(\%)\end{array}$ & Inf & Sup \\
\hline $\boldsymbol{H}_{\mathbf{0}}(\%)$ & Bovino & 11,8 & 1,45 & 12,3 & 9,95 & 13,6 \\
$\boldsymbol{H}_{\max }(\%)$ & Búfalo & 11,3 & 3,41 & 30,2 & 7,07 & 15,5 \\
& Bovino & $71,0^{\mathrm{a}}$ & 5,03 & 7,08 & 64,8 & 77,3 \\
$\boldsymbol{S}_{50}$ & Búfalo & $84,7^{\mathrm{a}}$ & 9,71 & 11,5 & 72,7 & 96,7 \\
$(\%$ de suero) & Bovino & 10,41 & 3,16 & 30,4 & 6,50 & 14,3 \\
$\mathbf{C H}_{50}$ & Búfalo & 8,72 & 1,58 & 18,1 & 6,74 & 10,7 \\
(dilución de suero) & Bovino & 10,2 & 2,48 & 24,4 & 7,14 & 13,2 \\
$\boldsymbol{n}$ & Búfalo & 11,8 & 2,18 & 18,5 & 9,08 & 14,5 \\
& Bovino & 4,48 & 1,29 & 28,8 & 2,88 & 6,08 \\
& Búfalo & 3,37 & 0,69 & 20,4 & 2,52 & 4,22 \\
\hline & & & & & &
\end{tabular}

Se halló que la actividad hemolítica máxima expresada como \% de hemólisis $\left(H_{\max }\right)$ fue mayor en presencia de $\mathrm{SBu}(\mathrm{p}<0.05)$. Por el contrario, no se hallaron diferencias entre los valores estimados de $n, S_{50}$ y $\mathrm{CH}_{50}$ en el suero de ambas especies.

\section{Cinética de crecimiento bacteriano en presencia de $\mathrm{SBo}$ y $\mathrm{SBu}$}

Se observó que en presencia de SBo y SBu, el desarrollo de la masa bacteriana de Escherichia coli (09-684) fue menor respecto del desarrollo observado en el medio de cultivo estándar ( $\mathrm{CMH})$, tal como se presenta en la Figura 3

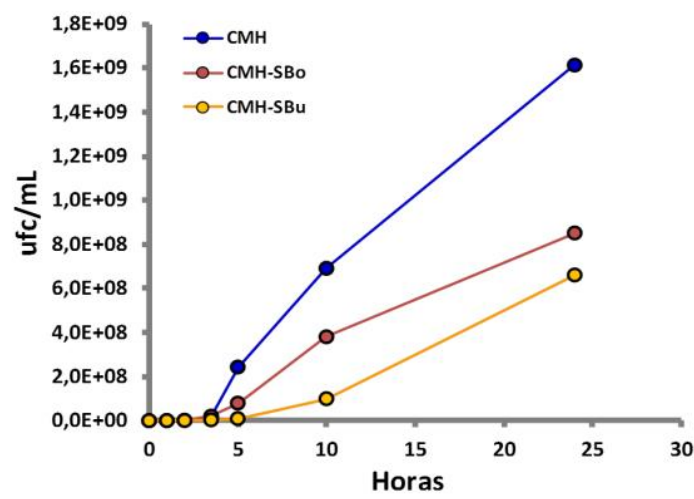

Figura 3: Gráfica en escala aritmética de las curvas de crecimiento bacteriano en función del tiempo de Escherichia coli (09-684) en Caldo Muller Hinton (CMH), Caldo Muller Hinton y suero bovino en proporción 50:50 (CMH-SBo) y Caldo Muller Hinton y suero de búfalo en proporción 50:50 (CMH$\mathrm{SBu}$ ). La población bacteriana se expresa como unidades formadoras de colonia/mL (ufc/mL). 
Al respecto, la mayor eficacia antibacteriana se observó en presencia de SBu, logrando reducir el desarrollo bacteriano en un $69,8 \%$ respecto de una eficacia del $47,2 \%$ obtenida en presencia de SBo (Tabla 2).

Tabla 2: Evaluación de la actividad antibacteriana intrínseca de suero de bovino y de búfalo sobre Escherichia coli (09-684) a partir de los resultados obtenidos en curvas de crecimiento bacteriano. La eficacia de los sueros de cada especie se expresa como porcentaje de reducción del desarrollo bacteriano respecto del desarrollo observado en el medio de cultivo estándar. $\mathrm{CMH}$ es caldo Muller Hinton, que es considerado aquí como medio de cultivo estándar, $\mathrm{CMH}$-SBo 50:50 es Caldo Mueller Hinton y suero bovino en proporción 50:50, CMH-SBu 50:50 es Caldo Mueller Hinton y suero de búfalo en proporción 50:50, $A B C$ es la integral de las concentraciones bacterianas expresadas como unidades formadoras de colonia/mL en función del tiempo (ufc/mL.h/mL), desde tiempo cero hasta las 24 horas.

\begin{tabular}{lccc}
\hline $\begin{array}{l}\text { Medio de } \\
\text { cultivo }\end{array}$ & $\begin{array}{c}\mathrm{ABC} \\
\text { (ufc/mL).h/mL }\end{array}$ & $\begin{array}{c}\text { Eficacia } \\
(\%)\end{array}$ & $\begin{array}{c}\text { Eficacia } \\
\text { relativa } \\
\text { (\%) }\end{array}$ \\
\hline CMH & 3736641 & Testigo & - \\
CMH-SBo 50:50 & 1974773 & 47,2 & 43,0 \\
CMH-SBu 50:50 & 1124498 & 69,8 & \\
\hline
\end{tabular}

\section{Discusión}

En este estudio, la actividad antibacteriana intrínseca del SBo y de SBu mediada por AcN y C, fue evaluada de manera indirecta mediante reacciones de inmunohemólisis de ERC enfrentados a concentraciones crecientes de suero de las dos especies. El ensayo de hemólisis-aglutinación, no aportó ningún tipo de información relevante para determinar si existían o no diferencias entre la actividad hemolítica mediada por AcN y $C$, ya que la máxima actividad hemolítica visible se observó a una dilución de 1:16 de los sueros de las dos especies (Figura 1).

Las diferencias entre los SBo y SBu pudieron ser determinadas analizando los datos de la cinética de hemólisis y ajustando los datos experimentales sin linearización con el modelo sigmoideo de respuesta máxima o de Hill.

Este modelo no solo permitió describir adecuadamente la curva de hemólisis (Figura 2), sino que también posibilitó estimar el valor de cuatro parámetros $\left(H_{0}, H_{\max }, S_{50}, n\right)$ cuya interpretación proporcionó información relevante acerca de la cinética de la actividad hemolítica del SBo y del SBu.

El valor de $H_{0}$ representó la hemólisis basal expresada como \% de hemólisis causada por los procedimientos mecánicos de la técnica, cuyos valores rondaron aproximadamente entre el $11 \%$ y el $12 \%$ en los sueros de ambas especies y que no deberían ser atribuidos a la actividad de ningún componente sérico.
De fundamental importancia fueron los valores de $\mathrm{H}_{\max }$ que permitieron determinar diferencias entre la magnitud de la actividad hemolítica de los sueros, siendo el SBu el que produjo mayor porcentaje de hemólisis $(84,7 \pm 9,71 \%)$.

La potencia del suero de cada especie para producir hemólisis fue estimada por el valor de $S_{50}$ (a partir del cual se estimó el valor de $\mathrm{CH}_{50}$ ), mostrando que tanto los valores de $\mathrm{S}_{50}$ y $\mathrm{CH}_{50}$ no presentaron diferencias entre especies.

Finalmente el valor de $n$, describió la sensibilidad de la respuesta no linear de la curva de hemólisis. En particular, los valores de $n$ observados en SBo $(4,48 \pm$ $1,29)$ y $\mathrm{SBu}(3,37 \pm 0,69)$, indicaron una actividad hemolítica de tipo "todo o nada", lo que significa que una pequeña diferencia de concentración de suero permitió pasar de un porcentaje de hemólisis basal al máximo valor de hemólisis posible.

El ajuste de los datos experimentales de la curva de hemólisis en función de concentraciones crecientes de suero utilizando el modelo de Hill, generó más información acerca de la cinética de hemólisis, que el que podría haberse obtenido caracterizado la actividad hemolítica de los sueros, estimando solamente el valor de $\mathrm{CH}_{50}$ con un procedimiento de cálculo basado en la linearización de los datos experimentales, como en el caso de la ecuación de Von Krogh propuesto por Mayer (1967), o con el método de interpolación líneal propuesto por Costabile (2010). De haber sido así, tanto la mayor actividad hemolítica del SBu respecto del SBo y la respuesta hemolítica tipo "todo o nada" de la cinética de hemólisis hubieran pasado inadvertidas.

En vista de lo hallado, podemos afirmar que el ajuste de los datos experimentales mediante regresión no lineal ponderada de mínimos cuadrados con el modelo de Hill es un procedimiento matemático más eficiente para obtener información acerca de la cinética del proceso hemolítico que los métodos clásicos basados en la linearización de los datos experimentales (Motulsky and Ransnas, 1987).

Los resultados obtenidos en la cinética de hemólisis tuvieron correlación con los resultados obtenidos en las curvas de crecimiento bacteriano de un inóculo de Escherichia coli (09-684) realizadas en un medio de cultivo estándar $(\mathrm{CMH})$ y enriquecido con $\mathrm{SBo}(\mathrm{CMH}$ : $\mathrm{SBo}$ ) y SBu (CMH: SBu).

Esta correlación se debió en primer lugar, a que en presencia de SBo y SBu se observó un menor desarrollo de la masa bacteriana respecto de lo observado en el medio de cultivo estándar ( $\mathrm{CMH})$, lo que puede ser explicado por la actividad de los factores de respuesta inmune innata ( $\mathrm{ACN}$ y $\mathrm{C}$ ) presentes en los $\mathrm{SBo}$ y $\mathrm{SBu}$, y en segundo lugar, porque la eficacia de esa actividad bactericida fue mayor en presencia de SBu $(69,8 \%)$ que en presencia de SBo $(47,2 \%)$. 
Las eficacias hemolítica y bactericida tanto del SBo como del SBu, fueron distintas, porque los porcentajes de hemólisis fueron mayores a los porcentajes de eficacia antibacteriana observados tanto en SBo como SBu.

Una de las explicaciones a esta diferencia de eficacia entre hemólisis y actividad bactericida, podría ser a causa de que los eritrocitos son células cuya membrana es una estructura mucho más frágil que la pared que protege a las bacterias de los desbalances osmóticos y de los factores adversos del ambiente, incluyendo la acción del $\mathrm{C}$.

En un segundo lugar, debería considerarse el hecho de que algunas bacterias como Escherichia coli han desarrollado estrategias para capturar inhibidores séricos del C e inactivar la acción de este (Dave et al., 2001; Horstmann et al., 1988). Al respecto, se ha demostrado que la proteína de membrana externa $\mathrm{A}(\mathrm{OmpA})$ de $E$. coli $\mathrm{K} 1$ se une a la proteína C4b (C4BP), la que es el principal factor inhibidor de la vía clásica del C, y que inactiva las fracciones C3b y C4b para evitar la actividad bactericida del suero (Prasadarao et al., 2002; Wooster et al., 2006). En tercer lugar, los eritrocitos no se replican y tienen tanto in vivo como in vitro una vida limitada (Franco, 2012), presentando tendencia $a$ ir lisándose a medida que el tiempo transcurre, mientras que lo opuesto ocurre con las bacterias, donde la totalidad de la población bacteriana observada al final de un ensayo de curva de crecimiento es la resultante del balance entre el crecimiento o desarrollo, la muerte y la supervivencia de las mismas (Blazewicz et al., 2014).

Los resultados obtenidos en este estudio mostraron una relación entre la actividad hemolítica de ERC y la reducción del desarrollo bacteriano de Escherichia coli, y que estas actividades in vitro fueron mayores en presencia de SBu que de SBo.

Si bien estos hallazgos tienen relación con el concepto popular de que el búfalo de agua tiene una respuesta inmune más eficaz que la del bovino, se necesitarán estudios adicionales para corroborar que estas diferencias respecto de la actividad de los factores de respuesta inmune innata ( $\mathrm{AcN}$ y $\mathrm{C}$ ) en las dos especies tiene in vivo un impacto biológico determinante en la resistencia temprana a las infecciones a favor del búfalo de agua.

\section{Agradecimientos}

Este estudio fue realizado como parte del proyecto 50120110100068 LI CAI+D 2011, el que fue financiado por la Universidad Nacional del Litoral como parte de la convocatoria de proyectos CAI+D 2011. También agradecemos al Dr. Hugo Ortega por permitirnos utilizar las instalaciones y el instrumental del
ICiVet Litoral (Instituto de Ciencias Veterinarias del Litoral), UNL-CONICET. Igualmente apreciamos la colaboración de todo el equipo de trabajo del mencionado instituto, sin la cual no hubiera sido posible realizar este estudio.

\section{Bibliografía}

Avrameas S. 1991. Natural autoantibodies: from 'horror autotoxicus' to 'gnothiseauton'. Immunol. Today 12: 154-159.

Arya A and Goel MC. 1992. Studies on activation and levels of haemolytic complement of buffalo (Bubalus bubalis). II. Alternate complement pathway activity in serum. Vet. Immunol. Immunopathol. 30: 411-418.

Baggot JD. 2001. The physiological basis of veterinary clinical pharmacology. Ed. Blackwell Science, London. 283 pp.

Baumgarth N, Herman O, Jager G, Brown L, Herzenberg L, Chen J. 2000. B-1 and B-2 cell-derived immunoglobulin M antibodies are nonredundant components of the protective response to influenza virus infection. J. Exp. Med. 192: 271280.

Baumgarth N, Tung J, Herzenberg, L. 2005. Inherent specificities in natural antibodies: a key to immunedefense against pathogen invasion. Semin. Immunopathol. 26: 347362

Baumgarth N. 2013. Innate-like B cells and their rules of engagement. Adv. Exp. Med. Biol. 785: 57-66.

Blazewicz SJ, Schwartz E, Firestone MK. 2014. Growth and death of bacteria and fungi underlie rainfall-induced carbon dioxide pulses from seasonally dried soil. Ecology 95: 11621172.

Costabile M. 2010. Measuring the 50\% Haemolitic Complement $\left(\mathrm{CH}_{50}\right)$ activity of serum. J. Vis. Exp. 37: e1923.

Dave S, Brooks-Walter A, Pangburn MK, McDaniel LS. 2001. $\mathrm{PspC}$, a pneumococcal surface protein, binds human factor $\mathrm{H}$. Infect. Immun. 69: 3435-3437.

Ehrenstein MR, Notley CA. 2010. The importance of natural IgM: scavenger, protector and regulator. Nat. Rev. Immunol. 10: $778-786$

Franco RS. 2012. Measurement of Red Cell Lifespan and Aging. Transfus. Med. Hemother. 39: 302-307.

Franck SM, Bosworth BT, Moon HW. 1998. Multiplex PCR for enterotoxigenic, attaching and effacing, and Shiga toxinproducing Escherichia coli strains from calves. J. Clin. Microbiol. 36: 1795-1797.

Firsov A, Sergey N, Vostrov S, Shevchenko A, Cornaglia G. 1997. Parameters of bacterial killing and regrowth kinetics and antimicrobial effect examined in terms of area under the concentration-time curve relationships: action of ciprofloxacin against Escherichia coli in an in vitro dynamic model. Antimicrob. Agents Chemother. 41: 1281-1287.

Giacomino N, Cerra M, Stiefel S, Gumiy D, Notaro U, Buffa E, Baroni E, Formentini E. 2011. Actividad bactericida intrínseca de suero bovino sobre cepas de Escherichia coli y Staphylococcus aureus. Revista FAVE - Sección Ciencias Veterinarias 10: 45-57. doi.org/10.14409/favecv.v10i2.1540

Giacomino N, Cerra M, Gumiy D, Stiefel S, Notaro U, Baroni E, Formentini E. 2012. Pharmacokinetic-pharmacodynamic 
modeling of antibacterial activity of cephalexin on Escherichia coli in presence of canine serum. Rev. Med. Vet. (Tolouse) 163: 431-440.

Goutelle S, Maurin M, Rougier F, Barbaut X, Bourguignon L, Ducher M, Maire P. 2008. The Hill equation: a review of its capabilities in pharmacological modelling. Fundam. Clin. Pharmacol. 22: 633-48

Grumach AS, Ceccon ME, Rutz R, Fertig A, Kirschfink M. 2014. Complement profile in neonates of different gestational ages. Scand. J. Immunol. 79: 276-281.

Hangartner L, Zinkernagel RM, Hengartner H, 2006. Antiviral antibody responses: the two extremes of a wide spectrum. Nat. Rev. Immuol. 6: 231-243.

Horstmann RD, Sievertsen HJ, Knobloch J, Fischetti VA. 1988. Antiphagocytic activity of streptococcal $M$ protein: selective binding of complement control protein factor $\mathrm{H}$. Proc. Nat. Acad. Sci. 85:1657-1661.

Jaskowski TD, Martins TB, Litwin CM, Hill H. 1999. Comparison of Three Different Methods for Measuring Classical Pathway Complement Activity. Clin. Diag. Lab. Immunol. 6: 137-139.

Matson K, Ricklefs R, Klasing K. 2005. A hemolysishemagglutination assay for characterizing constitutive innate humoral immunity in wild and domestic birds. Develop. Comp. Immunol. 29: 275-86.

Mayer M. 1967. Complement and complement fixation. In: E. Kabat \& M. Mayer (eds.), Experimental Immunochemistry, 2nd ed. Charles Thomas, Springfield. pp. 133-240

Moreno-Indias I, Dodds AW, Argüello A, Castro N, Sim RB. 2012. The complement system of the goat: haemolytic assays and isolation of major proteins. BMC Vet. Res. 8: 91-100.

Motulsky HJ, Ransnas LA. 1987. Fitting curves to data using nonlinear regression: a practical and nonmathematical review. FASEB J. 1: 365-374.

Lindoro AGB. 2010. Reacción hemolítica aguda. Rev. Mex. Med. Tran. 3: 18-21.

OIE - World Organisation for Animal Health. 2008. Pruebas para comprobar la esterilidad y la ausencia de contaminación de los productos biológicos. Capítulo 1.1.9. (pp. 1-11). En: Manual de la OIE sobre animales terrestres.

Oyekan PP and Barta O. 1980. Hemolytic assay for goat (caprine) and swine (porcine) complement. Vet. Immunol. Immunopathol. 1: 317-328.

Ochsenbein A, Zinkernagel R. 2000. Natural antibodies and complement link innate and acquired immunity. Immunol. Today 21: 624-630.

Prasadarao NV, Blom AM, Villoutreix BO, Linsangan LC. 2002. A novel interaction of outer membrane protein $A$ with $C 4 b$ binding protein mediates serum-resistance of Escherichia coli K1. J. Immunol. 169: 6352-6360.

Siroski P, Merchant M, Parachú Marcó MV, Piña $\mathrm{Cl}$, Ortega HH. 2010. Characterization of the serum complement activity of the broad-snouted caiman Caiman Latirostris (Crocodilia: Alligatoridae). Zool. Stud. 49: 64-70.

Siroski P, Russi N, Ortega H, Formentini E. 2015. In vitro evaluation of synergistic activity between ciprofloxacin and broad snouted caiman serum against Escherichia coli. Research in Veterinary Science. 98: 98-105.
Wooster DG, Maruvada R, Blom AM, Prasadarao NV. 2006. Logarithmic phase Escherichia coli K1 efficiently avoids serum killing by promoting C4bp-mediated $\mathrm{C} 3 \mathrm{~b}$ and $\mathrm{C} 4 \mathrm{~b}$ degradation. Immunology 117: 482-93. 